\title{
A novel R198H mutation in the glucose-6-phosphate dehydrogenase gene in the tribal groups of the Nilgiris in Southern India
}

\author{
R. Chalvam - P. S. Kedar $\cdot$ R. B. Colah $\cdot$ \\ K. Ghosh · M. B. Mukherjee
}

Received: 19 September 2007/ Accepted: 6 November 2007/Published online: 28 November 2007

(C) The Japan Society of Human Genetics and Springer 2007

\begin{abstract}
Glucose-6-phosphate dehydrogenase (G6PD) deficiency is the most common red cell enzymopathy among humans. In India, G6PD Mediterranean, G6PD Orissa, and G6PD Kerala-Kalyan are the three common mutations which account almost 90\% of G6PD deficiency. Here we describe G6PD Coimbra, an unreported variant from India, and a novel $593 \mathrm{G} \rightarrow \mathrm{A}$ mutation in exon 6 with an amino acid change of Arg 198 His, among the tribal groups of the Nilgiris in Southern India. Further, this novel mutation was structurally characterized and it was found that the mutation is located at the end of the coenzyme domain, which may cause enzyme instability.
\end{abstract}

Keywords G6PD · Mutation · Coimbra · Nilgiri · India

\section{Introduction}

Glucose-6-phosphate dehydrogenase (G6PD) is an X-linked enzyme which catalyzes the first step of the pentose phosphate pathway. G6PD deficiency is very common in humans and can lead to a variety of clinical manifestations ranging from neonatal jaundice to acute hemolytic anemia and to severe chronic non-spherocytic hemolytic anemia (Beutler 1994). More than 400 biochemical variants have been identified, suggesting vast genetic heterogeneity (Beutler 1991). However, not all these variants have been

R. Chalvam · P. S. Kedar · R. B. Colah · K. Ghosh ·

M. B. Mukherjee ( $\square)$

Institute of Immunohaematology (Indian Council of Medical

Research), 13th floor, New Multistoried Building,

K.E.M. Hospital Campus, Parel, Mumbai 400012, India

e-mail: drmalaybm@yahoo.com characterized at the molecular level. Also, variants which were thought to be biochemically distinct have proven to be identical at the molecular level (Sukumar et al. 2005).

The population of India is culturally stratified, broadly into tribals and non-tribals (caste). The tribals, who constitute $8.2 \%$ of the total population (2001 Census of India), are believed to be the original inhabitants of India (Majumder 2001). G6PD deficiency is common in those areas where malaria is endemic. In India, the prevalence of G6PD deficiency varies from 5.7 to $27.9 \%$ in different population groups. G6PD Mediterranean was found to be the commonest variant among Indian caste groups (Sukumar et al. 2004). However, there is little information about the mutations causing G6PD deficiency among the tribal groups of Indians. We have previously reported that G6PD Namoru $(208 \mathrm{~T} \rightarrow \mathrm{C})$ was the major polymorphic variant (70.4\%), followed by G6PD Kerala-Kalyan $(989 \mathrm{G} \rightarrow \mathrm{A}$ ), among the tribals of the Nilgiri hills in Southern India (Chalvam et al. 2007). In this study, seven G6PD deficient individuals who did not show the presence of either of these variants or other common Indian variants were characterized by sequencing and enzymatic modeling.

\section{Materials and methods}

A total of 1,125 male individuals from different tribal groups of the Nilgiri district in Tamilnadu were screened for G6PD deficiency by the DPIP dye decolorization method. Sixty-one $(5.4 \%)$ individuals were found to be G6PD deficient. Mutational analysis of 40 deficient individuals revealed that $28(70.4 \%)$ and $5(12.5 \%)$ had G6PD Namoru $(208 \mathrm{~T} \rightarrow \mathrm{C})$ and G6PD Kerala-Kalyan (989 $\mathrm{G} \rightarrow \mathrm{A}$ ), respectively, whereas seven individuals remained uncharacterized (Chalvam et al. 2007). 
Blood samples were collected in EDTA after obtaining informed consent from these seven male G6PD-deficient individuals from the tribal groups of Irulas and Kurumbas. DNA was extracted from the peripheral blood leukocytes by using the DNA midi kit obtained from Qiagen, Germany. Exonwise DNA sequencing was done on an automated ABI Prism 310 DNA sequencer (Applied Biosystems, CA, USA).

A ribbon plot of the structure of the G6PD monomer was obtained from the 3D structure of human erythrocyte G6PD (Au et al. 2000), crystallized in the active state (R-state), protein data bank code-1QKI. The model of the mutant form of R198H was obtained by changing the amino acid substitution at 198, replacing arginine by the positively charged histidine in the coenzyme-binding domain (residue 31-200) of the G6PD subunit, using the Deep View Swiss-PDB viewer (http://expasy.org/spdbv/). The new mutation R198H was substituted at the corresponding position in the human erythrocyte G6PD structure by using the in silico graphics program PyMOL (website: http://pymol.sourceforge.net/).

\section{Results}

\section{DNA sequencing}

Sequence analysis revealed a $\mathrm{C} \rightarrow \mathrm{T}$ transition at $\mathrm{nt} 592$ in exon 6, resulting in the substitution Arg $\rightarrow$ Cys at amino acid 198, which corresponds to G6PD Coimbra, in three individuals. A novel nt $593 \mathrm{G} \rightarrow$ A mutation in exon 6, with a predicted amino acid change of Arg $\rightarrow$ His at codon 198, was identified in four individuals. This new mutation was also confirmed by family study and was designated G6PD Nilgiri (Fig. 1). The frequency of G6PD Coimbra and G6PD Nilgiri was found to be 7.5 and $10.0 \%$, respectively.

\section{Enzyme modeling}

The novel (R198H) mutation found in our case is located at the coenzyme binding domain, as is shown in Fig. 2a. The 3D model of the human G6PD structure provided evidence that the substitution of arginine 198 for histidine results in an imidazole functional group which destroys the favorable contact with Glu 193, because a charged residue is replaced by a hydrophobic residue in the coenzyme domain and, also, it is very close to Glu 206 which is involved in salt bridges at the dimer interface (Figs. 2b, c). A close up view of the mutant protein in the helix (residue 193-210) is shown in

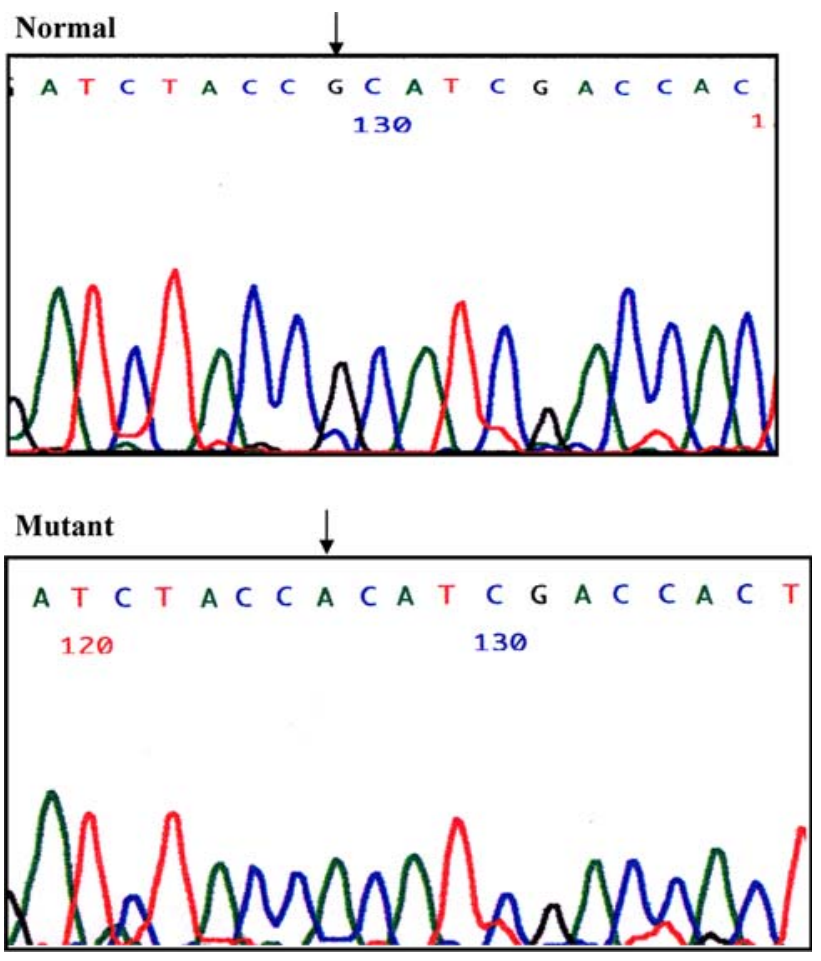

Fig. 1 Electropherogram of exon 6 of the G6PD gene showing the G6PD Nilgiri mutation at $593 \mathrm{G} \rightarrow \mathrm{A}(198 \mathrm{Arg} \rightarrow \mathrm{His})$, with the electropherogram of the normal gene

Fig. $2 \mathrm{~d}$ as a ball and stick model with the side-chain represented as a ribbon structure.

\section{Discussion}

G6PD Coimbra was first reported in a Portuguese boy with a family history of favism and the presence of this mutation was further confirmed in patients from Southern Italy (Corcoran et al. 1992). Subsequently, this mutation was also reported from South East Asia, mainly Malaysia and Indonesia (Ainoon et al. 2003; Kawamato et al. 2006). However, this mutation has not been reported from India. G6PD Coimbra is very close to the G6PD Mediterranean mutation within exon 6 and has similar kinetic properties, namely, high affinity for G6P and NADP and a high rate of dNADP and dG6P utilization compared with normal G6PD B. It has been suggested that the region encompassing the Coimbra and Mediterranean mutation is spatially close and involved in the enzyme's interactions with its substrate (Calabro et al. 1993).

The mutation at nt $593 \mathrm{G} \rightarrow \mathrm{A}$ is a hitherto unreported variant in exon 6. It is interesting to note that the amino acid change Arg $\rightarrow$ His is in the same codon 198 which is mutated in G6PD Coimbra (Arg $\rightarrow$ Cys). However, in G6PD Coimbra the mutation is at nt 592, the first base of 
Fig. 2 X-ray crystallographic structure of human erythrocyte G6PD monomer generated from the atomic coordinates of protein data bank entry $1 \mathrm{QKI}$ [PDB] using the program PyMOL. a The mutation at the coenzyme domain of the G6PD monomer. The hydrogenbonding network in the coenzyme domain between residues 198 and 193, indicated by dotted lines in $\mathbf{b}$, is lost in mutant c. A close-up view of the helix (residues 193-210) is shown in $\mathbf{d}$
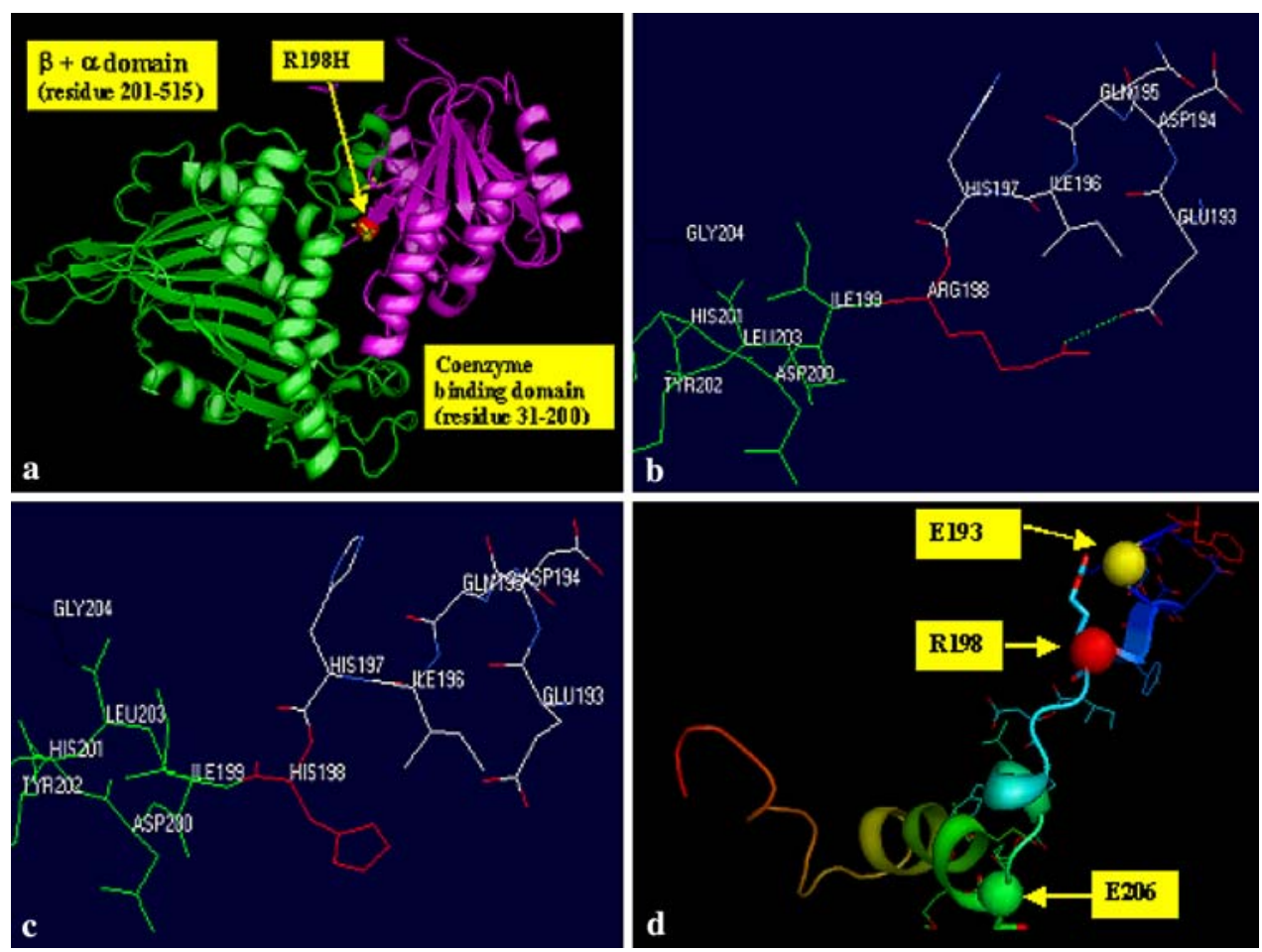

codon 198, whereas this new mutation is at the second base of the same codon. An earlier report has shown a similar situation involving codon 387 , where the mutation at the first base at nt 1159 was responsible for G6PD Guadaljara and that at the second base at nt 1160 was responsible for a mutant that had been identified as G6PD Beverly Hills (Beutler et al. 1996). Hence, the same amino acid can be affected by several mutations in the population with quite different effects. Unfortunately, a sufficient blood sample was not available for biochemical characterization of the residual enzyme.

The 3D model of human G6PD enzyme provided evidence that a large number of G6PD mutations are responsible for weakened dimer interaction giving rise to chronic non-spherocytic hemolytic anemia (CNSHA) (Naylor et al. 1996). We have analyzed the 3D structure of the novel mutation $\mathrm{R} 198 \mathrm{H}$ affecting the helix $\alpha$ n and it was found to be close to E206, which is involved in salt bridges at the dimer interface (Au et al. 2000). Arginine at 198, being a long straight chain amino acid, allows free movement of the residue at E206 to form the dimer, in contrast to replacement by histidine at the same position. Histidine, by virtue of its having a rigid aromatic imidazole functional group, may conceivably restrict the freedom of movement at residue 206 leading to weakened dimerization and consequent instability of the enzyme (Au et al. 2000). However, direct evidence for this is yet to be garnered. Because the $\mathrm{R} 198 \mathrm{H}$ mutation generates a more labile enzyme, which alters its $3 \mathrm{D}$ structure, the dimeric form is necessary for the catalytic activity of G6PD. Thus the decrease in the activity of G6PD renders the monomer more susceptible to thermostability, ultimately because of enzyme instability (Naylor et al. 1996).

In summary, both these variants have not previously been reported from India and possibly are not very polymorphic variants. However, further studies will have to be carried out to determine the prevalence and distribution of these variants in different population groups.

\section{References}

Ainoon O, Yu YH, Amir Muhriz AL, Boo NY, Cheong SK, Hamidah NH (2003) Glucose-6-phosphate dehydrogenase (G6PD) variants in Malaysian Malays. Hum Mutat 21:101

Au SWN, Gover S, Lam VMS, Adams MJ (2000) Human glucose-6phosphate dehydrogenase: the crystal structure reveals a structural $\mathrm{NADP}(+)$ molecule and provides insights into enzyme deficiency. Structure 8:293-303

Beutler E (1994) G6PD deficiency. Blood 84:3613-3636

Beutler E, Vulliamy TJ, Luzzatto L (1996) Hematologically important mutations: glucose-6-phosphate dehydrogenase. Blood Cells Mol Dis 22:49-56

Buetler E (1991) Glucose-6-phosphate dehydrogenase deficiency. N Engl J Med 324:169-174

Calabro V, Mason PJ, Filosa S, Givitelli D, Cittadella R, Tagarelli A, Martini G, Braneati C, Luzzatto L (1993) Genetic heterogeneity of glucose-6-phosphate dehydrogenase deficiency revealed by single strand confirmation and sequence analysis. Am J Hum Gent 52:527-536

Chalvam R, Mukherjee MB, Colah R B, Mohanty D, Ghosh K (2007) G6PD Namoru $(208 \mathrm{~T} \rightarrow \mathrm{C})$ is the major polymorphic variant in 
the tribal populations in Southern India. Br J Haematol 136:512513

Corcoran CM, Calabro V, Tamagnini G, Town M, Haider B, Vulliamy TJ, Mason PJ, Luzzatto L (1992) Molecular heterogeneity underlying the G6PD Mediterranean phenotype. Hum Genet 88:688-690

Kawamato F, Matsuoka H, Kanbe T, Tantular IS, Pusarawati S, Kerong HI, Damianus W, Mere D, Dachlan YP (2006) Further Investigations of glucose-6-phosphate dehydrogenase variants in Flores Island, eastern Indonesia. J Hum Genet 51:952-957

Majumder PP (2001) Ethnic populations of India as seen from an evolutionary perspective. J Biosci 26:533-545
Naylor CE, Rowland P, Basak AK, Gover S, Mason PJ, Bautista JM, Vulliamy TJ, Luzzatto L, Adams MJ (1996) Glucose 6phosphate dehydrogenase mutations causing enzyme deficiency in a model of the tertiary structure of the human enzyme. Blood 87:2974-2982

Sukumar S, Mukherjee MB, Colah RB, Mohanty D (2005) Two distinct Indian G6PD variants G6PD Jamnagar and G6PD Rohini caused by the same $949 \mathrm{G} \rightarrow \mathrm{A}$ mutation. Blood Cells Mol Dis 35:193-195

Sukumar S, Mukherjee MB, Colah RB, Mohanty D (2004) Molecular basis of G6PD deficiency in India. Blood Cells Mol Dis 33:141145 